\title{
Investigations of Chromium(III) and (VI) Ions Sorption on SIR by using Photoacoustic and DRS Methods
}

\author{
G. WOJCIK $^{a, *}$, Z. HUBICKI ${ }^{a}$ AND J. RYCZKOWsKI ${ }^{b}$ \\ ${ }^{a}$ Department of Inorganic Chemistry, ${ }^{b}$ Department of Chemical Technology \\ University of Maria Curie-Skłodowska, pl. M. Curie-Skłodowskiej 2, 20-031 Lublin, Poland
}

\begin{abstract}
Chromium is a major pollutant for the environment, usually as a result of some industrial pollution. Chromium is used in various industries such as metallurgical (steel, ferrous and nonferrous alloys), refractories (chrome and chrome-magnesite), and chemical (pigments, electroplating, tanning). For this reason, significant amounts of chromium pass into the environment and cause adverse ecological effects. In the present paper the investigations of solvent impregnated resin preparation was conducted. Photoacoustic and diffuse reflectance spectra were recorded for the prepared solvent impregnated resin. Photoacoustic spectra in the infrared area allow distinguishing the differences between the sorbent applied before and after the impregnation process. Impregnation of resin is a result of physical sorption of Aliquat 336 on macroporous Amberlite XAD 16.
\end{abstract}

PACS numbers: $82.80 . \mathrm{Kq}, 81.70 . \mathrm{Cv}, 82.50 .-\mathrm{m}$

\section{Introduction}

Aliquat 336 is a well known agent used for impregnation of polymeric sorbents for sorption of chromium(VI) ions $[1,2]$. Literature describes only a liquid phase during sorption of chromium(VI) ions, without investigation of solid phase and effects inside it. The photoacoustic method permits to describe a solid phase after impregnation while the diffuse reflectance spectroscopy (DRS) method permits to trace changing concentration of chromium(VI) ions in the solid phase. Therefore, possible application of both photoacoustic and DRS methods to study sorption of chromium(VI) on the prepared solvent impregnated resin (SIR) was investigated.

\section{Experimental}

\subsection{Characteristics of sorbent and extractant}

Amberlite XAD 16 is a commercial resin (Rohm \& Haas Co., France) with a macroporous structure and styrene-divinylobenzene skeleton (Fig. 1). Aliquat 336

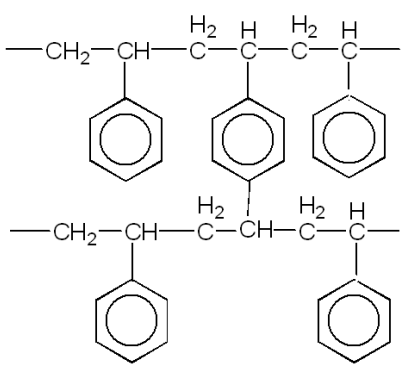

Fig. 1. The parts of skeleton of Amberlite XAD 16.

* corresponding author; e-mail: grzegorzwojcikumcs@wp.pl

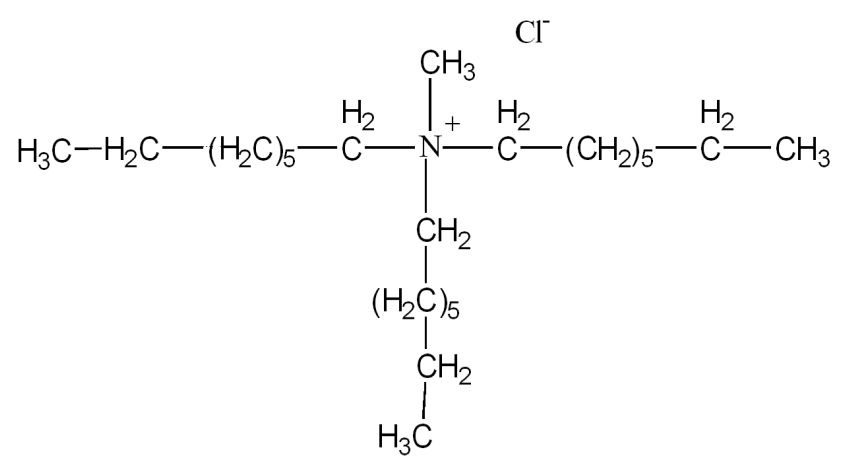

Fig. 2. The molecular formula of Aliquat 336.

is a trioctylmethylammonium chloride (Sigma-Aldrich) with the molecular formula shown in Fig. 2.

\subsection{Impregnation procedure}

Before the impregnation Amberlite XAD 16 was rinsed with methanol and then with water. Such a treatment allows to remove impurities. As a reaction vessel the $500 \mathrm{~cm}^{3}$ conical flask was used. $10 \mathrm{~g}$ of Aliquat 336 was put into the flask and dissolved in $250 \mathrm{~cm}^{3}$ of methanol. In the following step $10 \mathrm{~g}$ of Amberlite XAD 16 was added and all ingredients were shaken for $3 \mathrm{~h}$ at $293 \mathrm{~K}$. After impregnation, SIR was rinsed by deionized water. Finally, the resin was stored in water.

\subsection{Sorption investigation}

$0.6 \mathrm{~cm}$ diameter columns joined to the feeder by means of the ground glass joint were used in the dynamic method. They were filled with the proper water swollen solvent impregnated resin in the amount $5 \mathrm{~cm}^{3}$. Then proper solutions of chromium(VI) ions of the concentration $100 \mu \mathrm{g} / \mathrm{cm}^{3}$ were passed at the rate $0.35 \mathrm{~cm} / \mathrm{min}$ 
through the ion-exchanger bed. The eluate was collected in the $5,10,25 \mathrm{~cm}^{3}$ fractions and their chromium contents were determined. The contents of chromium(VI) ions were analysed by using 3 methods: atomic absorption spectroscopy (AAS) for chromium(III + VI) and two spectrophotometric methods for chromium(VI) or (III).

\subsection{Spectroscopic investigations}

The FT-IR photoacoustic (FT-IR/PA) spectra were recorded by means of a Bio-Rad Excalibur 3000MX spectrometer equipped with a photoacoustic detector MTEC 300 over the $4000-400 \mathrm{~cm}^{-1}$ range at the resolution of $4 \mathrm{~cm}^{-1}$ and maximum source aperture. The spectra were normalized with reference to the MTEC carbon black standard. Before each data collection, the PA cell was purged with dry helium for 5 min. Interferograms of 512 scans were averaged for each spectrum. The DRS spectra were measured by using the Specord M42 spectrometer equipped with a diffuse reflectance attachment produced by Carl Zeiss, Germany.

\section{Results and discussion}

In order to make surface characteristics of prepared SIR, the PA method was used. The spectra of Amberlite XAD16 were recorded before and after impregnation to estimate the efficiency of the applied procedure (Fig. 3).

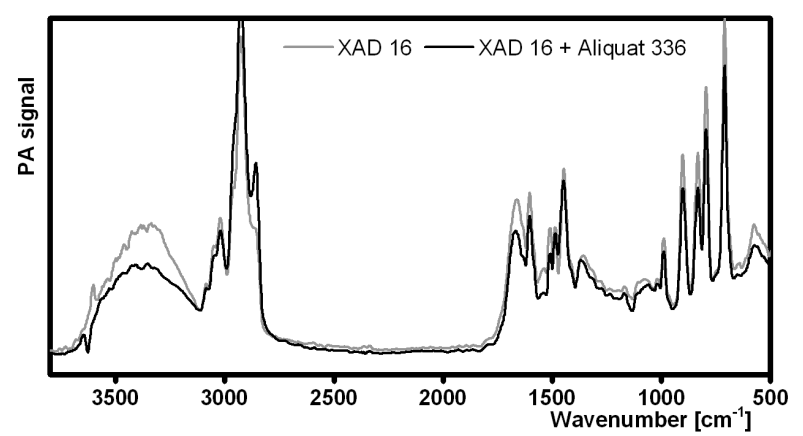

Fig. 3. The FT-IR/PA spectra of Amberlite XAD 16 before and after the impregnation process.

The broad band with the maximum located at $3430 \mathrm{~cm}^{-1}$ (Fig. 3) can be attributed to the stretching vibrations of adsorbed water. This band diminishes after the impregnation, which is related with decreasing hydrofilicity of prepared SIR. In the range 2900-2800 $\mathrm{cm}^{-1}$ some interesting differences were observed. There are carbon-hydrogen strong stretching vibrations from methylene and methyl groups. This part of spectrum is very similar to that for free trioctylmethylammonium chloride [3], and gives an undeniable proof that the surface of resins is modified after the impregnation. The concentration of Aliquat 336 in Amberlite XAD 16 was determined by using two methods: gravimetric and coulometric titration. The content of Aliquate 336 in Amberlite XAD 16 was $0.18 \mathrm{~g} / \mathrm{g}$.
The prepared SIR was used in further studies. Chromium(VI) ions were sorbed at three different values of $\mathrm{pH}: 1.5,3.5$ and 7 . The sorption process was led in transparent glass columns and the sun light fallen on the samples. The samples were dried and measured by the PAS method. The obtained spectra are shown in Fig. 4. There are no significant differences in the region from 3600 to $1200 \mathrm{~cm}^{-1}$ because in the recorded spectra the vibrations of nitrogen in quaternary ammonium salts are invisible. Since quaternary ammonium salts have no NH group they do not, of course, absorb at all in the IR region [4].

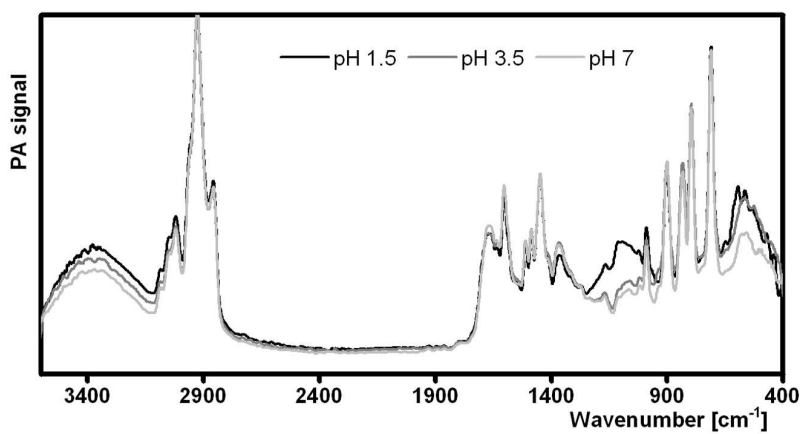

Fig. 4. FT-IR/PA spectra of Amberlite XAD 16 impregnated with Aliquat 336 after sorption of chromium(VI) ions at $\mathrm{pH} 1.5,3.5$ and 7 in the range $3600-400 \mathrm{~cm}^{-1}$.

The region of spectra between 1200 and $400 \mathrm{~cm}^{-1}$ is the most interesting. At $1100 \mathrm{~cm}^{-1}$ the signal is connected with $\mathrm{SO}_{4}^{2-}$ ions which come from $\mathrm{H}_{2} \mathrm{SO}_{4}$ used to adjust $\mathrm{pH}$ to the value 1.5 . At $942 \mathrm{~cm}^{-1}$ there exist signals related with $\mathrm{CrO}_{4}^{2-}$ ions. The signals appear only after sorption at the $\mathrm{pH}$ values 3.5 and 7 . It can be interpreted that chromium(VI) ions are reduced to the chromium(III) form at $\mathrm{pH}$ value 1.5 . Next evidence proving this theory are existing peaks 596 and $568 \mathrm{~cm}^{-1}$ in the spectra at pH 1.5 related with $\mathrm{Cr}$ (III) states (Fig. 5).

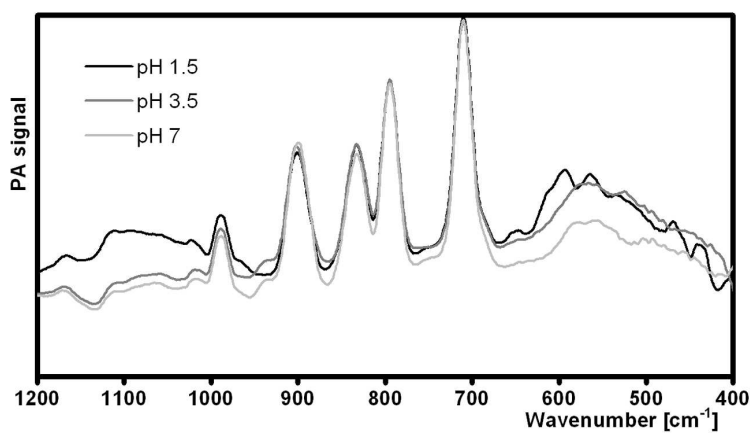

Fig. 5. The parts of FT-IR/PA spectra of Amberlite XAD 16 impregnated with Aliquat 336 after sorption of chromium(VI) ions at $\mathrm{pH} 1.5,3.5$ and 7 in the range 1200-400 $\mathrm{cm}^{-1}$. 
DRS was used in order to improve the results obtained by using the PAS method. The DRS method permits to trace changing of chromium(VI) ions in time during experiment.

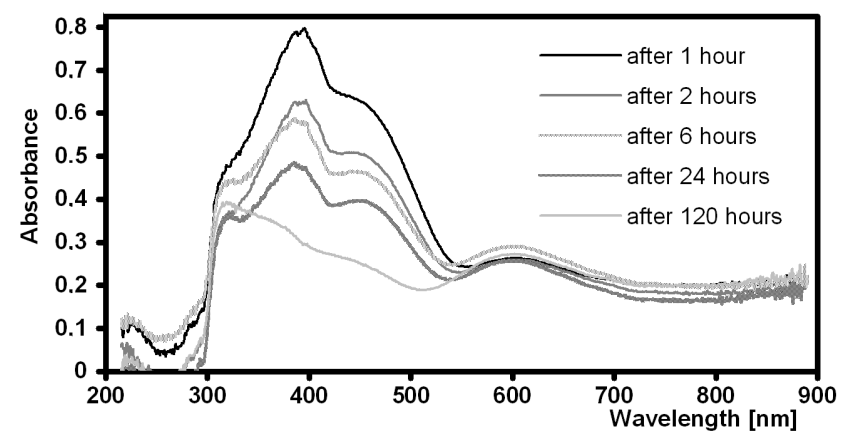

Fig. 6. The DRS spectra of Amberlite XAD 16 impregnated with Aliquat 336 after sorption of chromium(VI) ions measured after 1, 2, 6, 24, $120 \mathrm{~h}$.

In Fig. 6 the signal at $395 \mathrm{~nm}$ is related to existing chromium(VI) ions in the solid phase of SIR. During the experiment this signal decreases because chromium(VI) ions are reduced to chromium(III) ions. Chromium(III) ions pass back from the solid to the liquid phase. For each time 1, 2, 6, 24 and 120 h of sorption, concentration of chromium(III) and (VI) in solid phase were calculated on the basis of concentration in external solution. The concentration of chromium(VI) in external solution was less than $1 \mathrm{ppm}$ for $1 \mathrm{~h}$ and $0.1 \mathrm{ppm}$ for $120 \mathrm{~h}$ while the concentration of chromium(III) ions increases during experiment. The phenomenon is catalyzed by sun light because reduction does not exist or occur very insignificantly in the darkness.

\section{Conclusion}

Both PA and DRS methods are very useful in the investigations of SIRs [5-8]. The former provides the information about the mechanism of impregnation and sorption of chromium ions on Amberlite XAD 16, while the latter gives the data about sorption of chromium(VI) ions on the resin. Impregnation of resin is a result of physical sorption of Aliquat 336 on macroporous Amberlite XAD 16 from the acetone solution. The prepared and investigated SIR can be very useful for reduction of hazardous chromium(VI) in acidic sludge to a safer chromium(III) form using only natural sun light.

\section{References}

[1] N. Kabay, M. Arda, B. Saha, M. Streat, Reac. Funct. Polym. 54, 103 (2003).

[2] B. Saha, R.J. Gill, D.G. Bailey, N. Kabay, M. Arda, Reac. Funct. Polym. 60, 223 (2004).

[3] www.sigmaaldrich.com .

[4] G. Socrates, Infrared and Raman Characteristic Group Frequencies. Tables and Charts, Wiley, Chichester 2001.

[5] G. Wojcik, S. Pasieczna, Z. Hubicki, J. Ryczkowski, J. Phys. IV 137, 375 (2006).

[6] J. Mazur, B. Pustelny, Mol. Quant. Acoust. 28, 195 (2007).

[7] T. Starecki, Acta Phys. Pol. A 114, A-199 (2008).

[8] G. Wojcik, S. Pasieczna-Patkowska, Z. Hubicki, J. Ryczkowski, Europ. Phys. J. 154, 373 (2008). 